\title{
Using heat as a tracer to quantify surface water and groundwater interactions in the Baiyangdian wetland
}

\author{
Yushan Wang, Yonghui An, Xiaofan Qi, Dechao Yin \\ Center for Hydrogeology and Environmental Geology Survey, China Geological Survey, 071051, Baoding, Hebei, China
}

\begin{abstract}
Surface water and groundwater interactions play an important role in hydrological cycle in a wetland ecosystem. Understanding its mechanism and interaction magnitude imposes significant effects in wetland protection and management. In this study, a heat tracer method was taken in the Baiyangdian wetland as a case and temperature time-series data were collected for surface water and wetland sediment of $0.2 \mathrm{~m}, 0.6 \mathrm{~m}$ and $1 \mathrm{~m}$ respectively in 3 monitor sites. Then, a one-dimensional vertical steady heat transport model was applied to estimate surface water inflows to groundwater. The results showed that the leakage rates were $0.04-0.29 \mathrm{~mm} / \mathrm{d}$ and had a spatial and temporal variation. In the same monitor site, the leakage rate was higher in winter than it in summer. A total leakage amount for the Baiyangdian wetland was evaluated as 8.61 million $\mathrm{m}^{3} / \mathrm{d}$. The surface water leakage resulting from the model was subject to several uncertainties including sediments inhomogeneity and the impact of non-ideal conditions. Despite the uncertainties of the model, when correctly applied, heat tracer method is able to provide detailed information on the spatial and temporal distribution of surface water leakage.
\end{abstract}

\section{Introduction}

Wetland-groundwater interaction is an important component of wetland water and chemical budgets in managed and natural systems [1]. It is important to quantify wetland surface water discharge or recharge to groundwater in defining the role and function of these wetlands from an ecosystem and water quality perspective [2]. In recent years, a good deal of methods such as hydraulic head measurement, oxygen and hydrogen isotopes, water geochemistry and lake-groundwater model have been developed to estimate the exchange between wetland and groundwater [3]. However, the wetland surface water and groundwater interactions are controlled by both the basic geological and hydro-geological conditions and the variations of hydrological regimes, it is still a challenge to determine and quantify wetland and groundwater exchange [4].

Heat as a natural tracer in the water, can be measured easily and rapidly by a thermometer down. Heat tracer method has been widely used to study surface water and groundwater interactions in a river system [5]. Unlike in a riverine area, wetland surface water and groundwater interactions occur as diffuse seepage in the whole area through the lake bed rather than discrete flow from a point. The conditions are more complicated in a wetland system and heat tracer method is rarely used to quantify wetland surface water and groundwater interactions. In this paper, heat was used as a tracer to characterize and quantify surface water and groundwater exchange in the Baiyangdian wetland. The objectives are as follows: (1) to characterize temperature variations in surface water and lake sediments during summer and winter times; (2) to quantify wetland surface water leakage to groundwater in a point scale; (3) to test the usefulness of the heat method in a wetland system.

\section{STUDY AREA}

The Baiyangdian Lake in the central plain in Hebei Province is the largest fresh water wetland in North China, with a surface area of $366 \mathrm{~km} 2$. The wetland is located in a semi-arid and semi-humid climate region, where the annual mean rainfall is approximately $500 \mathrm{~mm}$. The monsoon season is from June to mid-September, accounting for more than $80 \%$ of annual precipitation. It is a semi-enclosed shallow water lake, is famous for large areas of reed and lotus. The lake was formed by water from several rivers such as the Fu, Xiaoyi and Tang at its southern, western and northern surrounding areas, among most of which have been dry for decades. The lake is important to the local economy as a source of food for surrounding riparian areas. In recent years, the quantity of water discharging into the lake has declined yearly. The lake water was seriously polluted and the water environment has deteriorated, causing ecosystem degradation. Over the last decades, human activities have significantly worsened ecological conditions. According to the monitor data, wetland water has a level around $6.3-7.2 \mathrm{~m}$ and is higher than groundwater level in surround areas, indicating that wetland surface water mainly leakage to groundwater. 


\section{METHODS}

Temperature was measured in January and June, 2019, when the difference between lake-water and groundwater temperatures was thought to be the greatest. Three temperature monitor locations were chose with a distance about $300 \mathrm{~m}$ from each other in the Northwestern of the wetlands. At each measurement location, the probe was pushed into the lake sediment by hand at a depth of $1 \mathrm{~m}$. Wetland surface water temperatures were measured in the middle of the water column at half-hour intervals. Sediment temperatures were measured at the depth of 0.2 $\mathrm{m}, 0.6 \mathrm{~m}$ and $1 \mathrm{~m}$ respectively at the same time interval as surface water. The wetland water depth and the GPS latitude longitude coordinates were recorded at each location. Wetland water depths ranged from 1 to $1.5 \mathrm{~m}$, and were higher in winter than in summer.

Based on the temperature measurements, vertical surface water and groundawgter fluxes were estimated by fitting the steady-state analytical solution of the one-dimensional conduction-convection equation to the measured temperature data described as follows [6]:

$$
\frac{\mathrm{T}_{\mathrm{Z}}-\mathrm{T}_{0}}{\mathrm{~T}_{\mathrm{L}}-\mathrm{T}_{0}}=\frac{\exp \left(-\frac{\mathrm{q}_{\mathrm{z}} \rho_{\mathrm{f}} \mathrm{c}_{\mathrm{f}}}{\mathrm{K}_{\mathrm{e}}} \mathrm{e}-1\right)}{\exp \left(-\frac{\mathrm{q}_{\mathrm{z}} \rho_{\mathrm{f}} \mathrm{c}_{\mathrm{f}}}{\mathrm{K}_{\mathrm{e}}} \mathrm{L}-1\right)}
$$

Where $\mathrm{Tz}$ is the lake sediments temperature $\left({ }^{\circ} \mathrm{C}\right)$ measured at the depth $\mathrm{z}(\mathrm{m}), \mathrm{T} 0$ is the wetland surface water temperature $\left({ }^{\circ} \mathrm{C}\right), \mathrm{TL}$ is the sediments temperature $\left({ }^{\circ} \mathrm{C}\right)$ at a given depth $\mathrm{L}(\mathrm{m}), \mathrm{qz}\left(\mathrm{m} \cdot \mathrm{s}^{-1}\right)$ is the vertical fluid flux, $\rho \mathrm{fcf}$ is the volumetric heat capacity of the fluid $\left(\mathrm{J} \cdot \mathrm{m}^{-3} \cdot{ }^{\circ} \mathrm{C}^{-1}\right)$ and $\mathrm{ke}$ is the effective thermal conductivity $\left(\mathrm{J} / \mathrm{m}^{-1} \cdot \mathrm{s}^{-1} \cdot{ }^{\circ} \mathrm{C}^{-1}\right)$. In this paper, an experimental value of $\rho \mathrm{fcf}$ and ke were given to 2.0 and 4.2 respectively.

\section{RESULTS AND DISCUSSIONS}

\subsection{Surface water and sediments temperature}

According to the monitor data, the air temperatures in the wetland ranged from $-8.1-26.2^{\circ} \mathrm{C}$ and had an increasing trend from January to June, 2019. Surface-water temperatures measured in the wetland during the lake-sediment temperature surveys ranged from 5.9 to
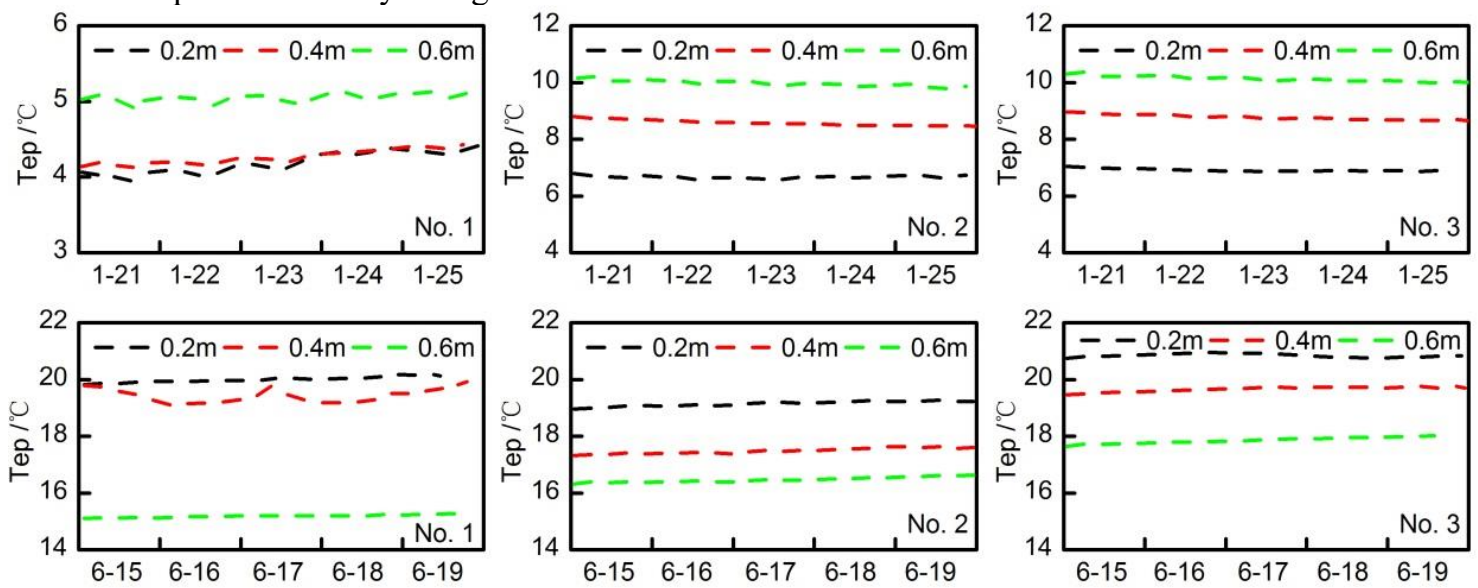

Fig. 1 The lake sediments temperatures variations in three monitor stations $22.2^{\circ} \mathrm{C}$, which showed a lower temporal variation. In the same period, a lag effect of the responses of surface water temperatures to air temperatures was observed. Lake sediment temperatures at the depths of $0.2 \mathrm{~m}, 0.6 \mathrm{~m}$ and $1 \mathrm{~m}$ ranged from $6.9-21.2^{\circ} \mathrm{C} 、 8.5-18.9^{\circ} \mathrm{C} 、 9.7-16.3^{\circ} \mathrm{C}$ respectively, which kept steady relatively. It can be seen that the deeper of the sediments, the more steady the temperature. In winter, the sediments temperature increased with the depth, while an opposite trend was observed in summer.

The hyporheic zone, which is an important interface between the surface water and groundwater, is an active zone in a river ecosystem. The temperatures of the sediments in hyporheic zone can be an indicator to the leakage rate. At areas of wetland surface water inflow to the groundwater, the sediment temperatures are cooler than surface-water temperatures in summer, while the cases are on the contrary in winter. At areas with either discharge from the lake to aquifers or little to no groundwater inflow, sediment temperatures are similar to surface-water temperatures. In winter, the area where the temperatures were relatively lower in the same depth, the leakage rates were higher. It was opposite in summer. The sediments temperatures in No. 1 location responded quickly to the surface water temperatures, indicating that more water leaked to groundwater. The sediments temperatures in No. 2 and No. 3 locations kept steady, indicating a week interaction between surface water and groundwater.

Generally, the higher leakage rates indicate that the sediments between surfaces water and groundwater have a higher conductivity. In this conditions, The temperature of sediments were near to that of surface water and the depth of the hyporheic zone was deeper. The vertical variations of the temperatures in the sediments from the No.2 monitor station showed that the extent of the temperature variations decreased with the depth, then kept in a steady trend. In addition, the depth of the hyporheic zone in the No. 2 station were lower than that of No.1 and No.2 station, which indicated that the leakage rates were less too. It can be inferred that the surface water leakage rate was controlled by complex factors such as lithology, the thickness of sediments, groundwater levels as well as water levels of lake. 

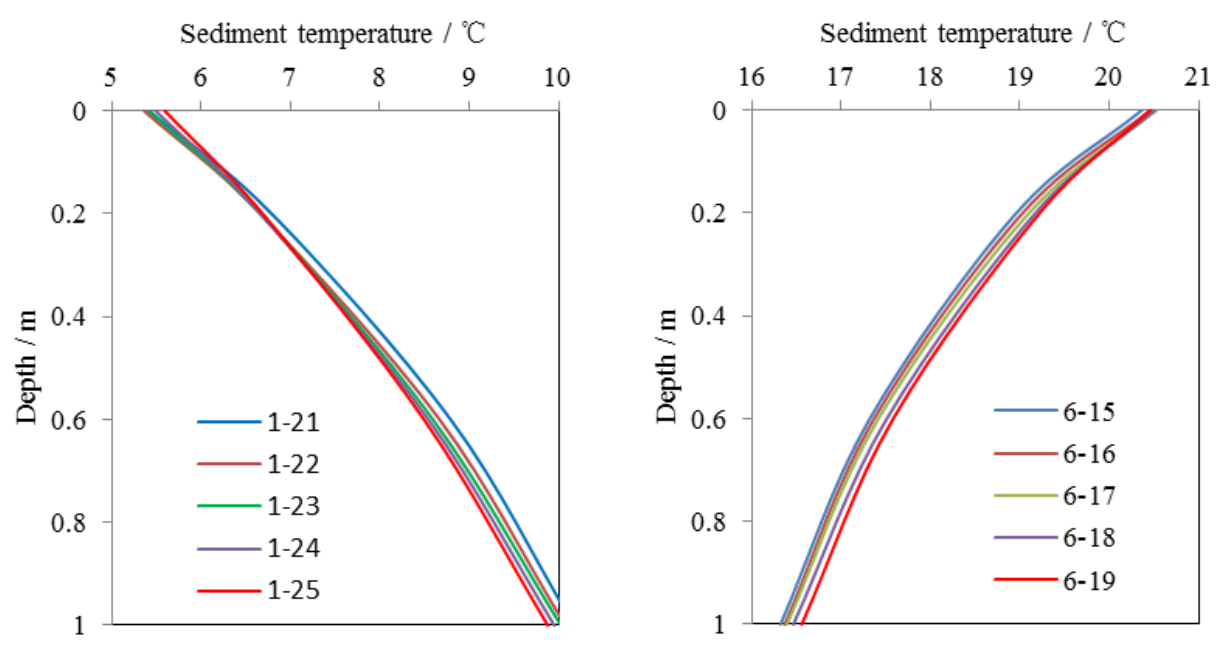

Fig. 2 The vertical temperatures profiles from the No. 2 monitor station

\subsection{Surface water leakage estimation}

Leakage rates of surface water to groundwater were estimated for three monitor locations in different period. In winter, the leakage rates of No.1, No. 2 and No. 3 locations were $0.18-0.29 \mathrm{~mm} / \mathrm{d}, 0.11-0.15 \mathrm{~mm} / \mathrm{d}$, $0.07-0.13 \mathrm{~mm} / \mathrm{d}$ respectively. In summer the values were $0.09-0.12 \mathrm{~mm} / \mathrm{d}, 0.06-0.10 \mathrm{~mm} / \mathrm{d}$ and $0.04-0.07 \mathrm{~mm} / \mathrm{d}$ respectively. The leakage rates had a spatial variation, in the same period, it was highest in No.1 station, followed by No. 2 and No.3 stations, indicating that the sediments were inhomogeneous strongly. It also had a temporal variation, in the same station, surface water leakage rates were greater in the winter, whereas the lowest ones were obtained during the summer. The average leakage rate during the monitor period was $0.118 \mathrm{~mm} / \mathrm{d}$, on the basis of which, the total leakage amount for the Baiyangdian wetland could be estimated as an annual value of 861 million $\mathrm{m}^{3}$.

\subsection{The usefulness of heat tracer method}

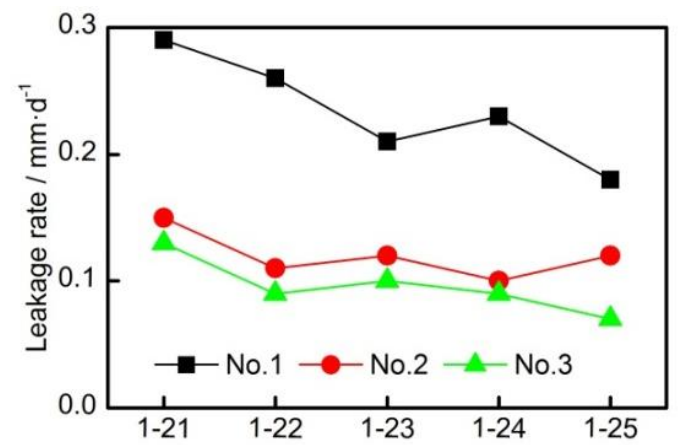

The temperature of water and sediments can be measured continually and heat transport models had been developed, making heat tracer method used widely in the hydrology and hydrogeology studies. The results of field investigations described in this research show that under favorable conditions, the temperature distribution in monitoring locations can be used to determine vertical surface water leakage rates to groundwater and can provided detail information of spatial and temporal variation.

Due to sediments inhomogeneity and the impact of non-ideal conditions, the using heat as tracer to estimate wetland surface water leakage to groundwater has some limitations and can produce misleading values. To make it more useful, some steps should be applied. Firstly, the temperature monitor location should be taken according to the lithology of lake sediments, especially in the old channels of rivers. Secondly, the distribution of monitor stations can be optimized, more monitor profiles were suggested to take to get the information of spatial variations. At last, heat tracer method must be tested by mass balance method to make sure it is accurate.

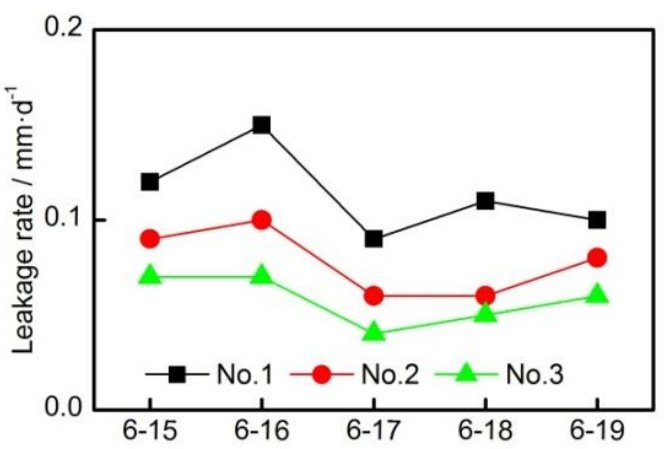

Fig. 3 The leakage rates for three monitor stations in the winter and summer

\section{CONCLUSIONS}

The temperatures were different in wetland surface water and lake sediments. In winter, the sediments temperature increased with the depth, while a opposite trend was observed in summer. During the monitor period, the surface water leakage rates were $0.04-0.29 \mathrm{~mm} / \mathrm{d}$ and experienced high spatial and temporal variations, with an average rates of $0.118 \mathrm{~mm} / \mathrm{d}$. The total leakage amount for the Baiyangdian wetland was estimated as an annual value of 861 million $\mathrm{m} 3$. Heat tracer method is a very cost-effective tool to understand wetland surface water and groundwater interactions although it has some uncertainties. When correctly used, it is able to provide detailed information on the spatial and temporal distributions of surface water leakage. 


\section{Acknowledgments}

This research was supported by China geological Survey project (No. 20190300). We thank Lei G,

Qing W X, and Zhen X R for collecting field data, and the anonymous reviewers for insightful comments that improved an early version of the manuscript.

\section{References}

1. Paces J B, Wurster F C. J. Hydrol. 517, (2014).

2. Schwerdtfeger J, Hartmann A, Weiler M. Hydrol. Processes. 30, (2016).

3. Devit K J, Hill A R. Hydrol. Processes, 11, (1997).

4. Min J H, Perkins D B, Jawitz J W . Wetlands, 30, (2010).

5. Arriaga M A, Leap D I, Hydrogeol. J. 14, (2006).

6. Taylor C A, Stefan H G. J. Hydrol. 375, (2009). 